\title{
Frame Structure and Engineering Applications of the Multisource System Cloud Service Platform of Monitoring of the Soft Rock Tunnel
}

\author{
Fengnian Wang $\mathbb{D}^{1,2}$ Songyang Yin $\mathbb{D}^{1,},{ }^{1,2}$ Aipeng Guo $\mathbb{D}^{2},{ }^{2}$ Zhicai Wang, ${ }^{3}$ Meng Mi, ${ }^{1,2}$ Gan Qi, ${ }^{4}$ \\ Juan $\mathrm{Ma}^{4}{ }^{4}$ and Haijiang Zhang ${ }^{2}$ \\ ${ }^{1}$ School of Mechanics and Civil Engineering, China University of Mining \& Technology (Beijing), Beijing 100083, China \\ ${ }^{2}$ State Key Laboratory for Geomechanics and Deep Underground Engineering, China University of Mining e Technology (Beijing), \\ Beijing 100083, China \\ ${ }^{3}$ Gansu Changda Highway Co., Ltd, Gansu 730030, China \\ ${ }^{4}$ China Geological Environment Monitoring Institute, No. 20, Dahui Temple, Haidian District, Beijing 100081, China
}

Correspondence should be addressed to Aipeng Guo; bqt1900606055@student.cumtb.edu.cn

Received 24 December 2020; Revised 20 January 2021; Accepted 1 February 2021; Published 15 February 2021

Academic Editor: Feng Xiong

Copyright $\odot 2021$ Fengnian Wang et al. This is an open access article distributed under the Creative Commons Attribution License, which permits unrestricted use, distribution, and reproduction in any medium, provided the original work is properly cited.

Throughout engineering construction, large deformation disasters in soft rock tunnels are encountered increasingly frequently. Therefore, structural health monitoring not only ensures accurate construction management but also provides a basis for dynamic adjustment of the support structure. The existing monitoring technology has certain shortcomings, such as poor antiinterference ability, non-real-time operation, and great security risks. Consequently, high-precision real-time monitoring has become a key scientific issue in tunnel engineering. For this work, multisource information fusion technology was adopted, while data security reserve systems, such as cloud server (ECS) based on the fiber Bragg grating multisource sensing system, cloud database (RDS), and cloud website, were embedded into the No. 2 inclined shaft of the Muzhailing tunnel. Based on the negative Poisson's ratio (NPR) anchor cable control technology for large deformation of the soft rock in the No. 2 inclined shaft of the Muzhailing tunnel, reasonable and effective intelligent monitoring was carried out for tunnel construction. Monitoring and early warning cloud service platforms, based on the Internet of Things and cloud technology, could quickly produce query and statistic tunnel monitoring information. The monitoring system provided the collection, transmission, storage, processing, and early warning information sending of data, such as NPR anchor cable axial force, steel arch stress, deep surrounding rock displacement, surrounding rock deformation, and contact pressure between primary support with secondary lining. This monitoring system ensured construction safety and provided monitoring application case support for the related problems of similar projects.

\section{Introduction}

In recent years, the construction of railway and highway tunnels in China has been abruptly developed [1-3]. Due to the special influence of the tunnel construction conditions and environment, many unpredictable factors exist $[4,5]$. An effective monitoring work in the construction is conducive to the supervision and management of the entire construction link, in combination with the promotion of construction safety and construction quality [6-8]. Large deformation or collapses often occur throughout in tunnel construction with soft surrounding rock [9-11], resulting in major safety accidents and economic losses. With the development of high precision, high intelligence, and diversified monitoring equipment, as along with the demand for fine management in each link of tunnel construction, many scholars have paid increased attention to tunnel safety monitoring. Chang and colleagues dealed with using wireless sensor network (WSN) in the application of the tunnel environmental monitoring purpose in the Snow Mt. Tunnel for Fire Exam testing [12- 
14]. Ding and colleagues presents a real-time safety early warning system to prevent accidents and improve safety management in underground construction, based on the "internet of things" (IoT) technology [15]. Through monitoring of the settlement and clearance convergence deformation of the Wolong tunnel construction vault, Pan and colleagues predicted the dangerous situation timely, adjusted the construction plan according to the monitoring results [16]. Based on a 3D laser scanner and processing algorithm for point cloud data, Jiang and colleagues presented a technology for measuring the 3D deformation of a deep tunnel in the Jinchuan No. 2 Mine to predicting deformational performance and determining the reasonable support opportunity [17].

Fiber Bragg grating (FBG) sensor technology is characterized by strong antielectromagnetic interference capability, wide measurement range, low transmission loss, high precision, and strong real-time performance. It has been proved as especially suitable for large projects, such as dams, tunnels, bridges, and highways, which require real-time monitoring of multiple parameters (strain, temperature, and vibration) [18-20]. Ding Yong and colleagues realized real-time distributed remote settlement monitoring of subway shield tunnels through FBG sensor pasting upon the aluminum alloy inclination-measuring tube surfaces [21]. Wang and colleagues encapsulated the FBG strain sensor in colloidal material and explored the surrounding rock strain distribution under the support step excavation, support full section excavation, and no support full section excavation through model experiments [22]. Zhu and colleagues proposed the method of continuous monitoring of surrounding rock deformation through the fiber Bragg grating displacement sensor assembly into a series, to obtain the axial displacement distribution at any distance within the large-scale monitoring line, which had certain reference significance for geotechnical engineering deformation monitoring [23]. Pan and colleagues built a monitoring system through embedded FBG strain sensor utilization, based on the strong anti-interference capability of FBG, verifying the feasibility and advantages of FBG sensor in the safety secondary lining structure monitoring of the water diversion tunnel [24]. Cai utilized the fiber Bragg grating sensing technology in the secondary lining and surrounding rock pressure monitoring of a tunnel, utilizing the method of nonlinear regression analysis, to predict and warn the possible disruptions within the tunnel [25]. Tao Zhigang and colleagues established the Newtonian force change monitoring and early warning system through multisource information fusion technology utilization, which satisfied the requirement for landslide disaster monitoring and early warning within a complex environment [26]. The latter systems provided a rich platform for data collection, transmission, management, analysis and release for the monitoring, and warning of engineering disasters, while a significant amount of research results was obtained. However, for the new tunnel support technology for large deformation control technology of soft rock tunnels through NPR anchor cable utilization, the monitoring methods and evaluation system were relatively deficient.

In this work, based on the support design scheme of NPR anchor cable for large deformation of the soft rock in the No.
2 inclined shaft of the Muzhailing tunnel, the axial force of anchor cable, steel arch stress, and deep displacement as well as the pressure of primary support with second lining was monitored with the ECS (elastic compute service) and RDS (relational database service), with which multisource information release and interaction technology were integrated. The improvement of intelligence, adaptability, safety, and stability of the entire monitoring system could provide technical reference for tunnel construction monitoring and early warning under various complex environments in the future.

\section{Distributed Sensing Technology Based on Fiber Bragg Grating (FBG)}

Fiber Bragg grating (FBG) sensors were produced through the refractive index change of the fiber core to produce small periodic modulation. When the temperature or stress changed, the fiber produced axial strain, which increased the grating period, whereas the core layer and cladding radius became lower-sized. The refractive index of the fiber was changed through the photoelastic effect, consequently causing the grating wavelength deviation. Through the drift $\lambda_{B}$ amount measurement, the deformation or temperature change amount of the fiber can be obtained as equation (1):

$$
\Delta \lambda_{B}=2 n_{e f f} \Lambda,
$$

where $n_{\text {eff }}$ is the effective refractive index of the fiber, and $\Delta$ is the grating period. The strain and temperature had a good linear relationship with the center wavelength and were independent of each other. The correlation equation is presented as equation (2).

$$
\Delta \lambda_{B}=\alpha_{\varepsilon} \Delta \varepsilon+\alpha_{\mathrm{T}} \Delta T,
$$

where $\Delta \lambda_{B}$ is the grating wavelength drift, $\Delta \varepsilon$ is the axial strain variable of grating, and $\Delta T$ is the temperature change of the grating. The $\alpha_{\varepsilon}$ and $\alpha_{T}$ are the strain coefficient and thermal expansion coefficient, respectively. Based on the linear relationship among strain, temperature, and the offset of grating wavelength, the strain variables of the structure under testing were calculated. The principle of the FBG sensor system is presented in Figure 1.

If the temperature remains unchanged, the relationship between the strain on FBG and the central wavelength shift can be expressed as equation (3):

$$
\Delta \lambda_{B}=\Delta_{\varepsilon}\left(1-P_{e}\right) \lambda_{B},
$$

where $\lambda_{\mathrm{B}}$ is the central wavelength of the grating, and $P_{e}$ is the effective photoelastic coefficient. If the FBG sensors with different initial center wavelengths were connected in series on the same fiber, the quasidistributed monitoring of strain at each point on the fiber could be realized. Quasidistributed FBG sensor technology mainly encapsulated the fiber Bragg grating strain gauge into a variety of different types of fiber Bragg grating sensors, which were arranged and installed on the object under testing, to realize the various deformation parameter measurements of this object under testing. 


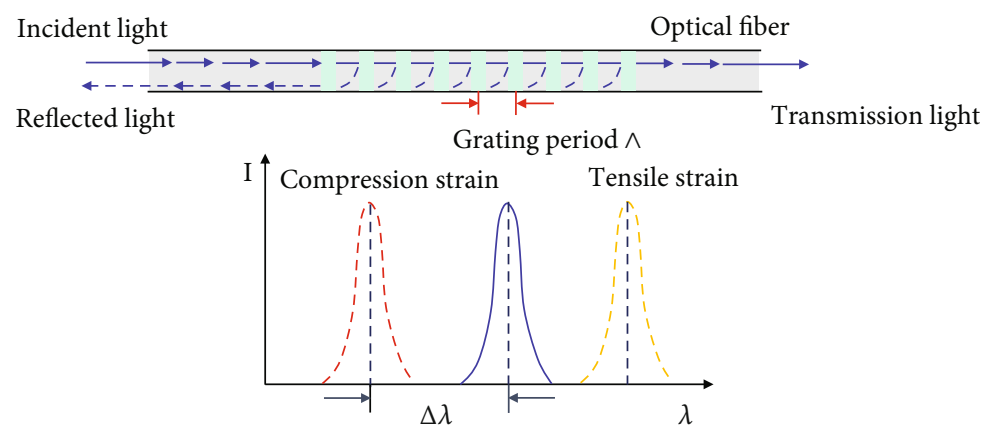

FIgURe 1: Principle of the FBG sensing technique [27].

\section{System Unit of Soft Rock Tunnel Monitoring}

3.1. Axial Force Monitoring of the NPR Anchor Cable. In order to adapt to the requirement increase for bolt devices in underground engineering projects, the constant resistance and large deformation anchor cable were developed, also known as the NPR anchor cable [28-30]. The corresponding structure is presented in Figure 2(a). It was composed of a steel strand, a tray, a constant resistance device, and a lockset as well as other parts. Among these parts, the constant resistance sleeve was composed of a constant resistance body and steel casing, as presented in Figure 2(b). The constant resistance sleeve has a negative Poisson ratio effect. The constant resistance body moves under the axial force action of the anchor cable and interacts with the constant resistance sleeve, to realize constant resistance sliding. When the anchor cable stress is lower than the constant resistance value, the anchor cable is in the elastic working state. When the anchor cable stress exceeds the constant resistance value, the NPR material constant resistance device generates slip deformation through the cone body to absorb energy, to ensure that the anchor cable does not break and continues to have the corresponding bearing capacity [31, 32].

During the NPR anchor cable support within the soft rock tunnel, the stress state was measured by the NZ-FBGALG fiber grating anchor cable axial force sensor, as presented in Figure 3(a). The sensor precision was $0.1 \mathrm{kN}$, and the maximum range was $500 \mathrm{kN}$. The measured data of the sensor could be obtained through the fiber grating demodulator utilization, to obtain the wavelength date that caused the deformation of the steel barrel and consequently, the calibration coefficient was substituted, to calculate the load value of the fiber grating anchor cable force sensor. Since the external diameter of the NPR anchor cable constant resistance sleeve was up to $75 \mathrm{~mm}$, this axial force sensor required a larger diameter. It was necessary for the two steel pallets to be utilized at the same time, to clamp the sensor in the middle, to maintain the axial force test as more accurate and stable. The installation mode of the sensor is presented in Figure 3(b).

3.2. Deep Displacement Monitoring of the Surrounding Rock. The fiber Bragg grating multipoint displacement meter could reflect the plastic zone expansion depth of the surrounding rock after the support structure completion. It was of high significance to evaluate the restraining effect of the high pretension support structure on the surrounding rock loose zone. The displacement sensor of NZ-FBG-FPG is presented in Figure 4(a). The sensor accuracy was $0.1 \mathrm{~mm}$, and the maximum range was $1500 \mathrm{~mm}$.

Through grouting, the sensor end was fixed with the deep surrounding rock. The surrounding rock deformation pressure acted on the sensor free end, while the relative motion between the sensor and the fixed end was realized through the transfer rod, for the central wavelength of the fiber Bragg grating to change. After the monitoring data was demodulated by the fiber grating demodulator, the displacement variation of each point was obtained. NZ-FBG-FPG fiber grating displacement sensor as well as the corresponding installation method is presented in Figure 4(b).

3.3. Pressure Monitoring of Steel Arch Frame. As a new method to control large deformation of the soft rock in the tunnel, the support effect of the NPR anchor cable was of high significance to the optimization design of steel arch frame parameters. Simultaneously, the monitoring data could effectively reflect the stability of the primary support structure. The NZ-FBG-SSG fiber Bragg grating strain sensor is presented in Figure 5(a), with a sensor accuracy of $0.1 \mathrm{MPa}$ and a maximum range of $500 \mathrm{MPa}$. The sensor was installed upon the groove surface of the steel arch through spot welding, as presented in Figure 5(b). The steel arch was subjected to deformation and bending by surrounding rock pressure, which changed the central wavelength of the fiber Bragg grating stress sensor. The stress characteristics of the steel arch could be obtained with a demodulation instrument.

3.4. Pressure Monitoring of Primary Support with Secondary Lining. The monitoring of contact pressure between primary support with secondary lining could not only contribute to the pressure distribution evaluation of the primary support system on the secondary lining, but it also played an important role in the thickness and strength design optimization of secondary lining concrete. As presented in Figure 6(a), the NZ-FBG-ALG pressure sensor had a precision of $0.01 \mathrm{MPa}$ and a maximum range of $5 \mathrm{MPa}$. The sensor was welded to the steel pallet through spot welding, while the steel pallet was welded to the two-wire steel cage, to achieve a tight fitting between the sensor and the waterproof plate. The installation method of the sensor is presented in Figure 6(b). 


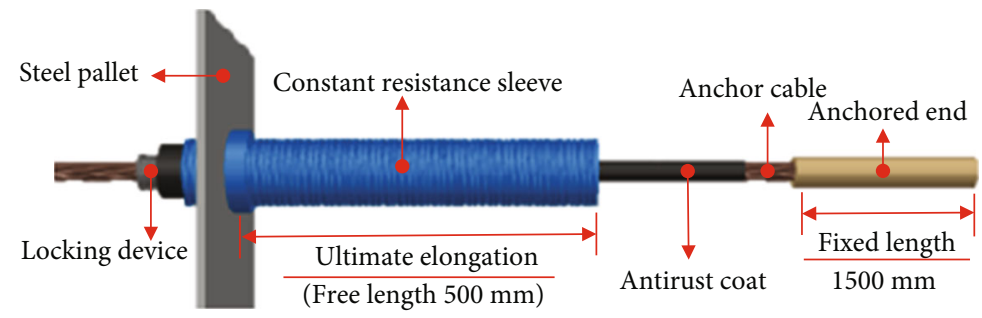

(a)

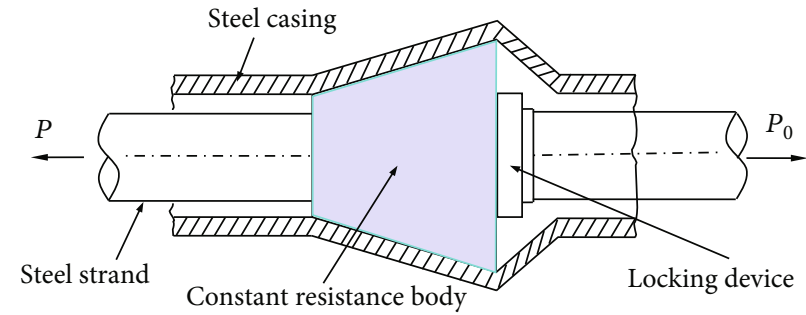

(b)

FiguRE 2: Structural of constant resistance and large deformation anchor cable.

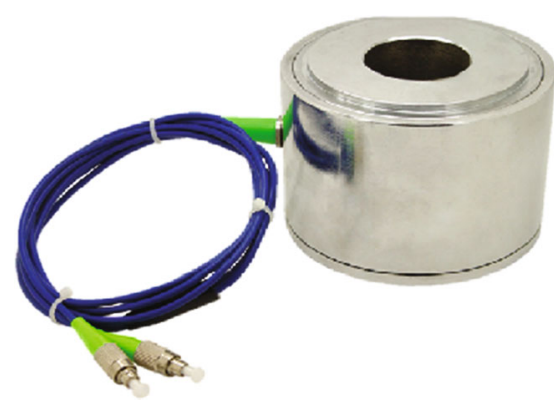

(a)

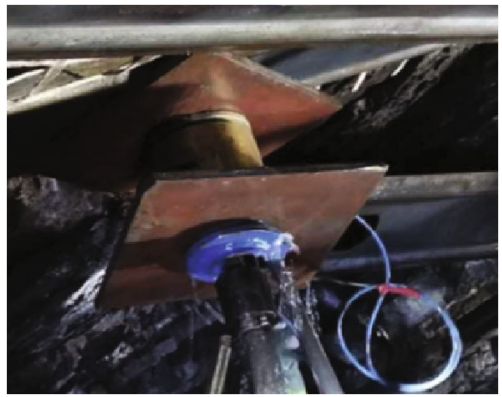

(b)

FIGURE 3: Fiber Bragg anchor cable force sensor.

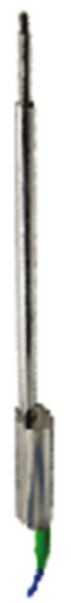

(a)

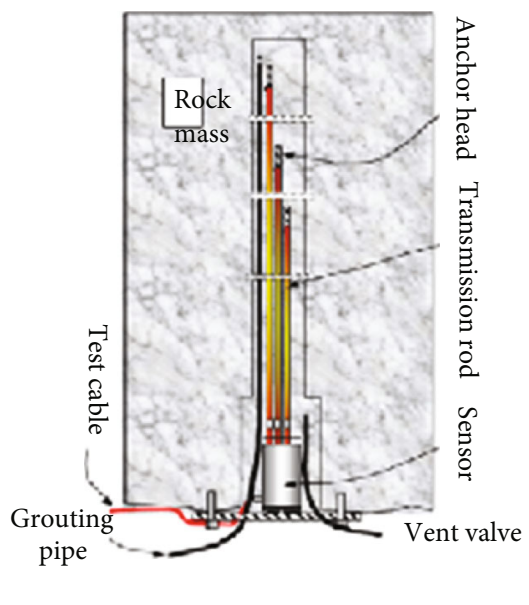

(b)

FIGURE 4: Fiber Bragg multipoint displacement sensor.

3.5. Data Acquisition Unit. Quasidistributed optical fiber sensing technology is utilized for centralized parametric management of multisource information through a series of sensors. Different types of sensors are grouped and con- nected in parallel to the demodulator. Demodulator data is encrypted and transmitted to the server or cloud platform through GPRS module or Beidou module, which is convenient for terminal equipment, through which, to the data 


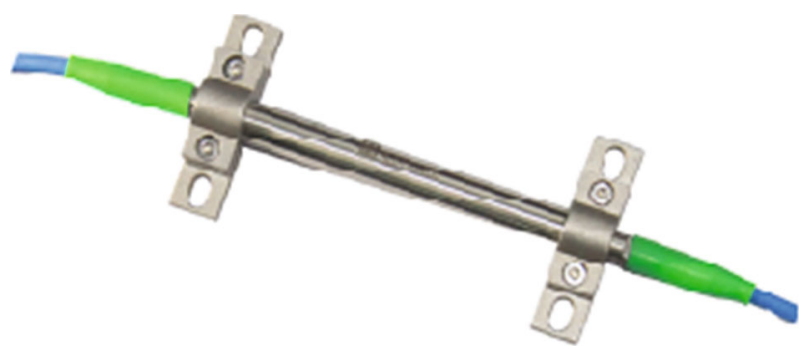

(a)

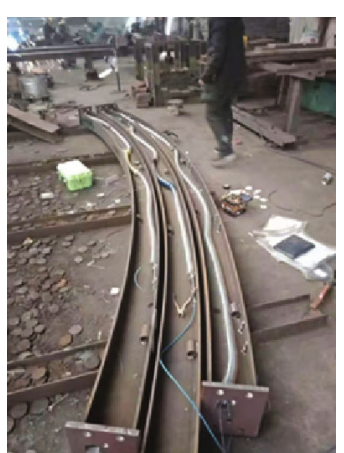

(b)

FIGURE 5: Fiber Bragg steel arch strain gauge.

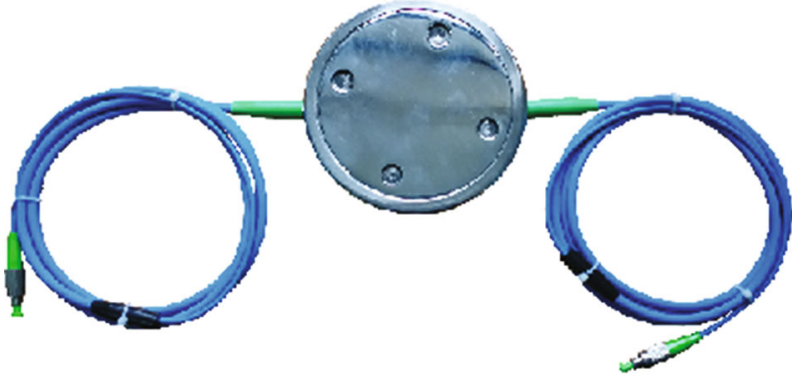

(a)

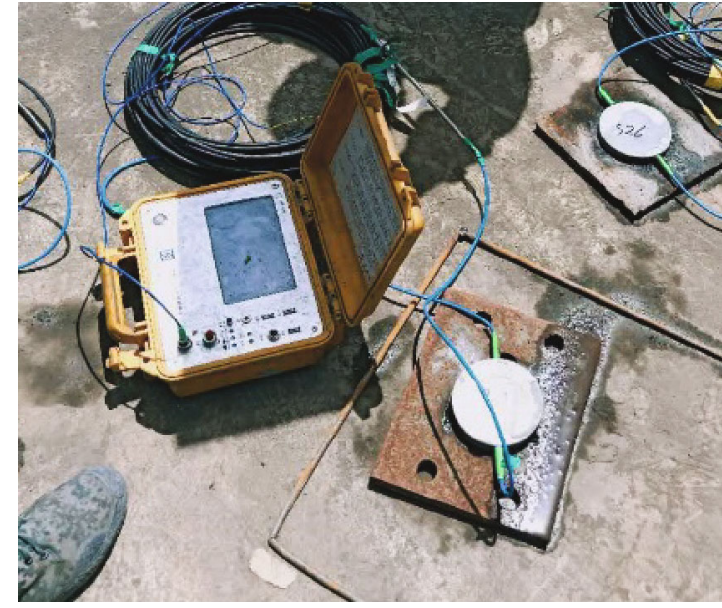

(b)

FiguRe 6: Fiber Bragg potential side pressure sensor.

are extracted and analyzed. The fiber potential demodulator of NZ-FBG-A02 is presented in Figure 7.

3.6. Deformation Monitoring of the Surrounding Rock. Monitoring of the surrounding rock deformation is a necessary parameter for tunnel deformation control. The deformation of the surrounding rock was observed with the Leica TD06Plus-2R500 total station, as presented in Figure 8(a). When it is deemed necessary, a 3D laser scanner is utilized to measure the deformation of the surrounding rock section, as presented in Figure 8(b), with a measurement accuracy of up to $0.1 \mathrm{~mm}$. Since the data of total station and 3D laser scanner cannot be transmitted online in real time, the deformation data dynamic management of the surrounding rock could be realized through manual input.

\section{Cloud Platform Construction of the Tunnel Multisource Information Monitoring System}

4.1. Multisource Information Monitoring System Platform Framework. The platform of the tunnel multisource information monitoring system is positioned and developed to promote the accurate collection, efficient calculation, and real-

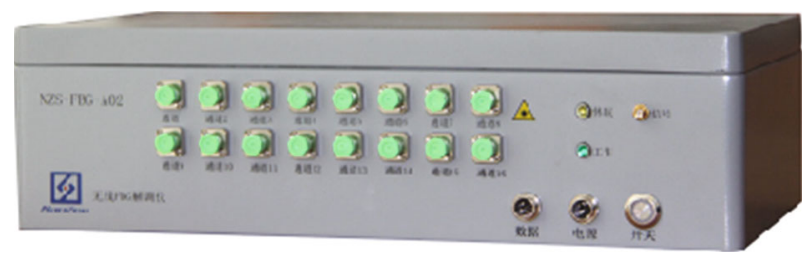

Figure 7: Fiber potential demodulator of NZ-FBG-A02.

time release of monitoring information. The construction of a system platform is presented in Figure 9.

4.2. Composition and Function of System. Based on cloud computing technology, the tunnel monitoring cloud service platform was established. The intelligent remote multisource tunnel monitoring system was divided into four layers: data layer, transmission layer, computing layer, and output layer, as presented in Figure 10, while the specific functions were

(1) Perception layer: it was composed of data acquisition subsystems, such as NPR anchor cable anchoring force monitoring, surrounding rock deformation monitoring, deep surrounding rock displacement 


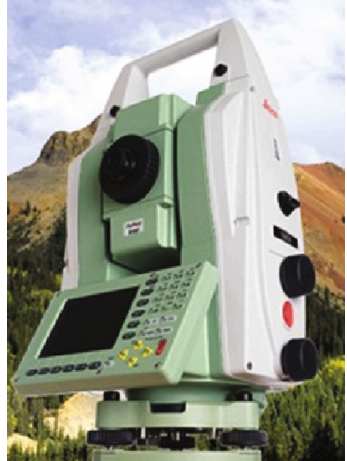

(a)

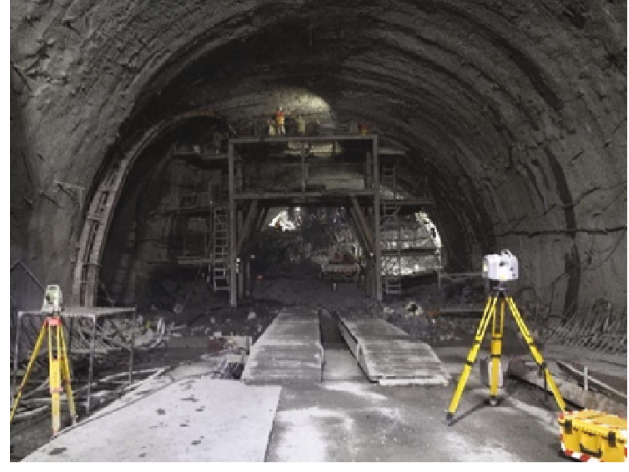

(b)

FIgURE 8: Three-dimensional tunnel laser scanner.

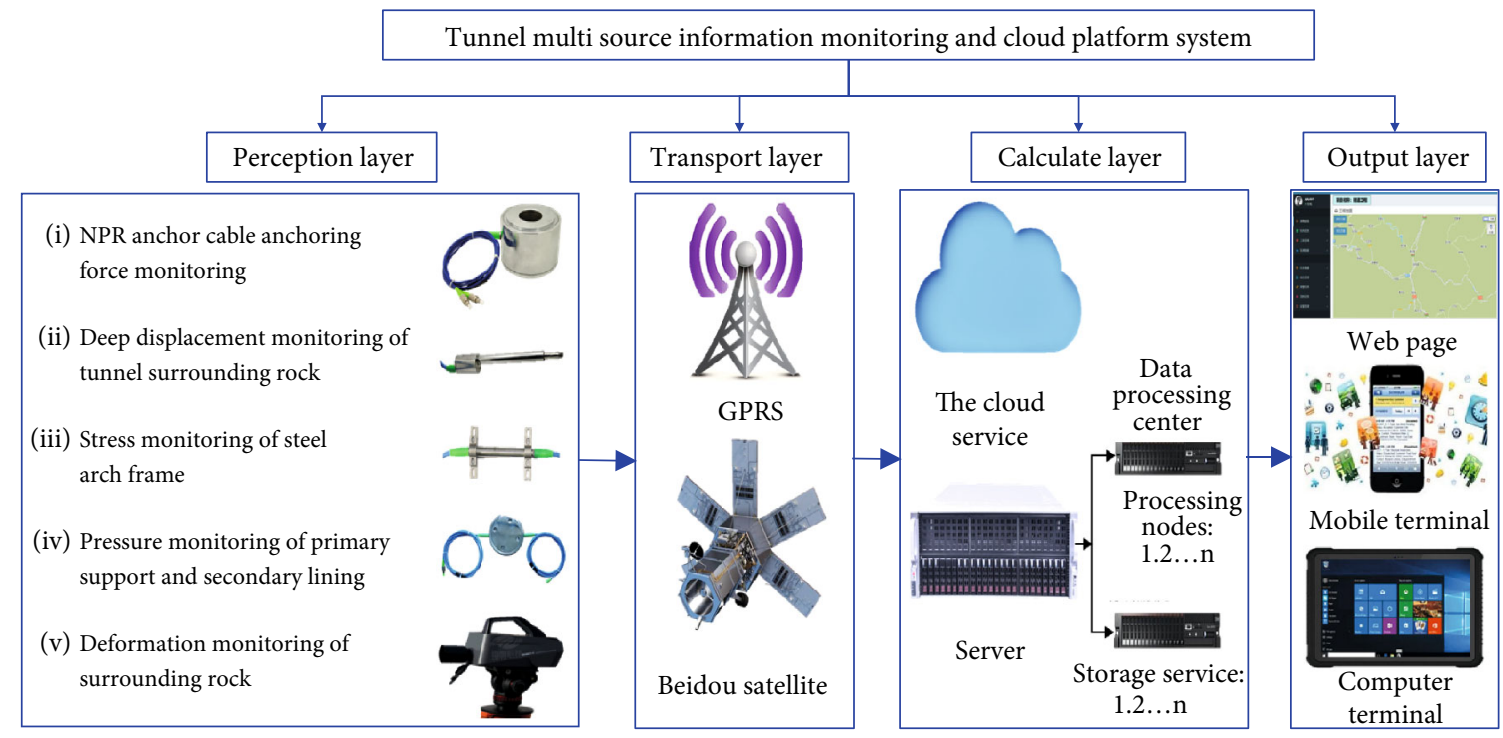

Figure 9: Data transmission topology diagram of the multisource monitoring system.

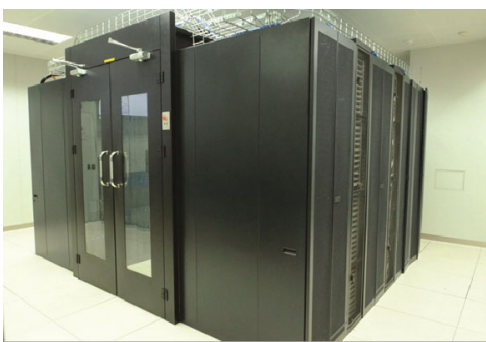

(a)

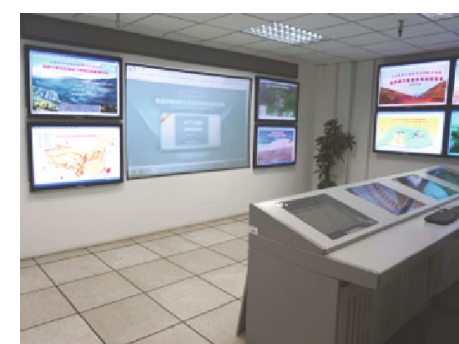

(b)

FIGURE 10: Tunnel intelligent remote monitoring data center management system and release system.

monitoring, steel arch frame pressure monitoring, primary support with secondary lining pressure monitoring, data acquisition equipment, data transmission module, and power supply system

(2) Transmission layer: through the dual-channel communication mode adoption of GPRS and Beidou satellite, according to the principle of "first come, first served", the data obtained after automatic discarding would be avoided to receive data duplication. When it was found that one signal communication was disconnected, the other system would automatically switch to run, to ensure that the data would not be lost

(3) Calculation layer: the received data was compiled and secondary processed, while the data could be calculated and stored for the terminal device to call. The cloud platform automatically stored the data in the 


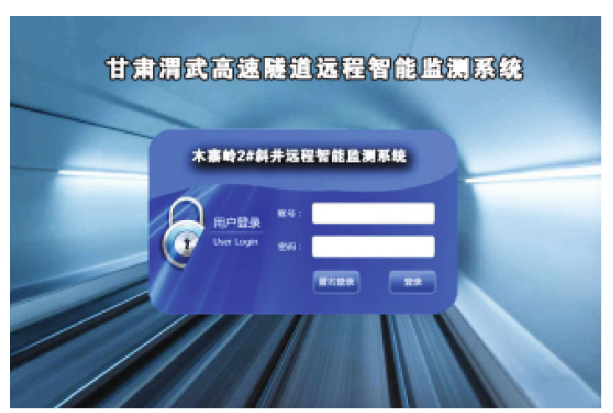

(a)

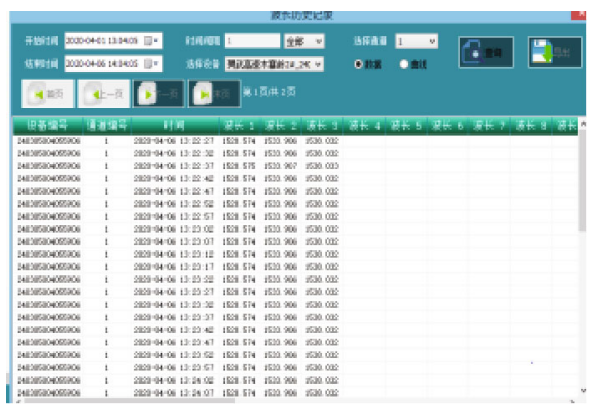

(b)

FIGURE 11: Tunnel intelligent remote real-time monitoring system login and system interface.

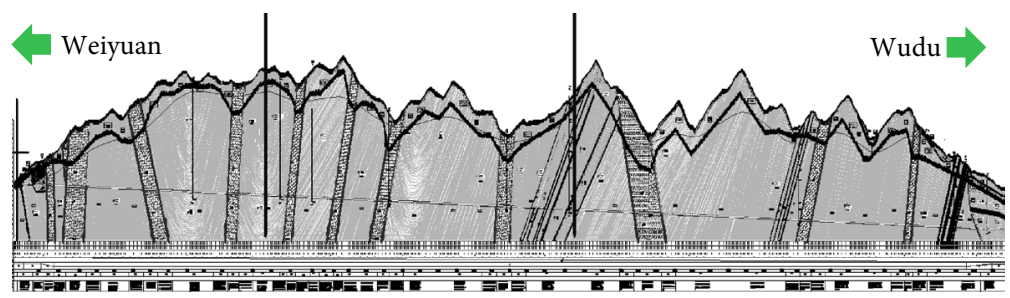

Figure 12: Sectional view of the Muzhailing tunnel.

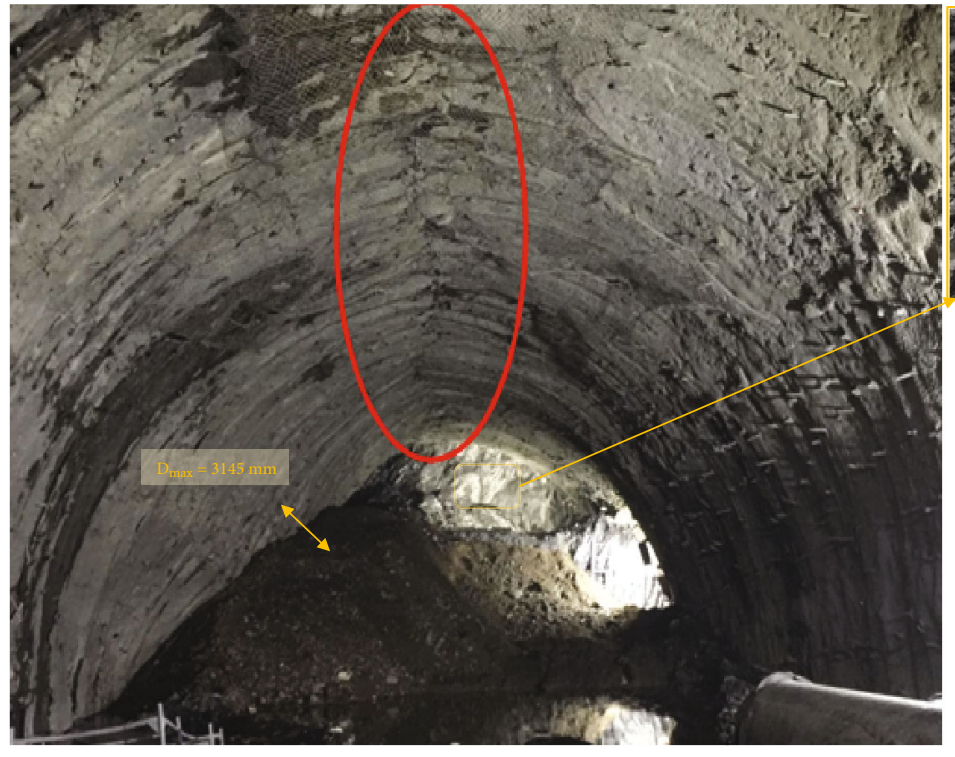

(a)

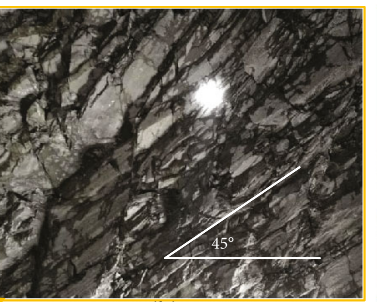

(b)

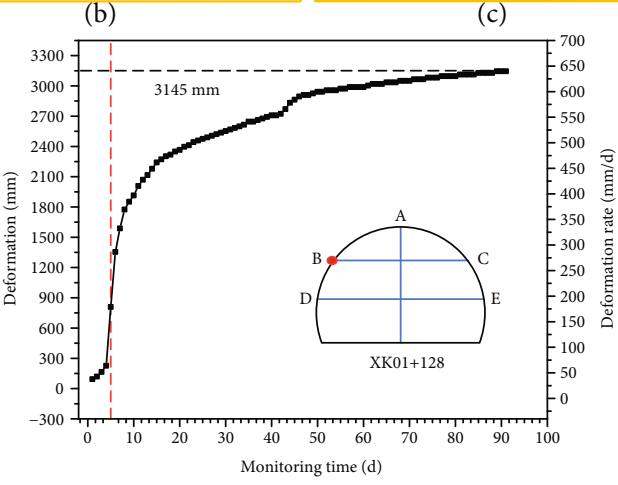

$\rightarrow$ Deformation of point $B$

FIGURE 13: Large deformation of the surrounding rock in the No.2 inclined shaft of the Muzhailing tunnel.

cloud database after the receiving program of the cloud server received the data, which was convenient for the cloud website and the monitoring workstation retrieval. When the data volume was high, big data processing and analysis could be realized with the cloud platform contribution

4.3. Cloud Platform Service System Advantages. With the advent of the cloud computing and big data era, traditional data servers will gradually be replaced by cloud computing data centers. The intelligent tunnel monitoring system will be installed to utilize the cloud server of Aliyun, which will have the following advantages $[33,34]$ :

(1) Stability: cloud disk data reliability of the cloud server reaching $99.9 \%$, automatic down migration, automatic snapshot backup, and data recovery as convenient and fast. A traditional server is limited by the hardware configuration limitations and the influence of machine room conditions, requiring manual 


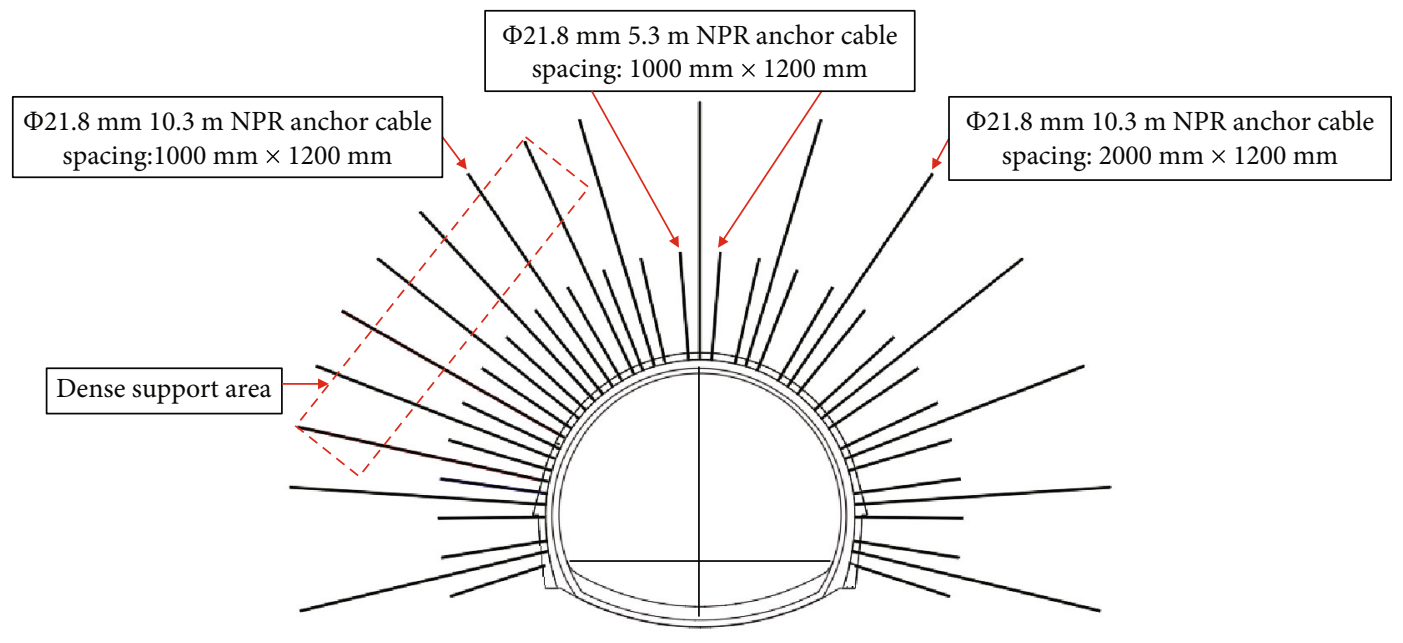

(a)

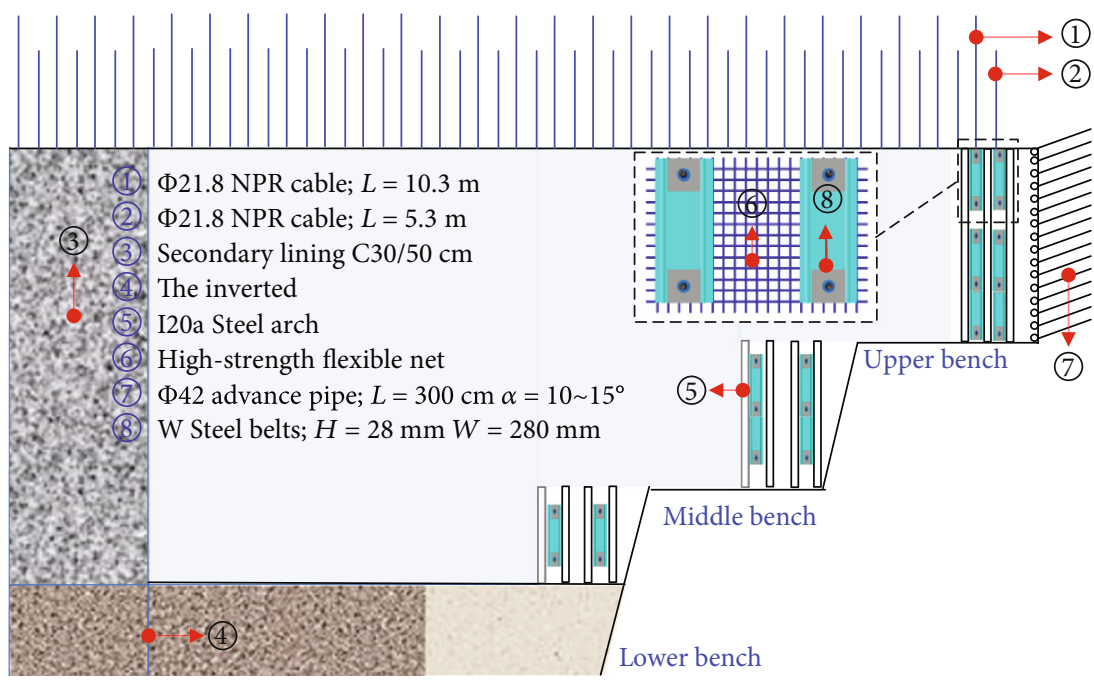

(b)

FIGURE 14: Design of the NPR anchor cable support in the No. 2 inclined shaft of the Muzhailing tunnel and three bench support design.

backup, while the manual data recovery is proven difficult and time-consuming

(2) Flexibility: a cloud server could freely configure CPU, memory, and bandwidth, as well as upgrade the configuration at any given time, to ensure that the data will not be lost. The traditional server is a fixed configuration. If the configuration is modified, the hardware is required to be upgraded. The cycle is long, and the service stops

(3) Security: the cloud server comes with security measures, such as distributed denial of service (DDOS) protection, Trojan horse detection, and antiviolence cracking, to ensure the safety and reliability of big data. Traditional servers require extra security to be purchased and deployed

(4) Extensibility: the elastic compute service (ECS) could be seamlessly connected to a variety of cloud prod- ucts, while providing complete computing, storage, security, and other solutions for system applications in a sustainable manner. Traditional servers cannot guarantee the scalability and sustainability of data growth

4.4. System of Information Publishing. The information publishing system of the tunnel intelligent remote multisource monitoring system mainly includes three parts: the central control system, the network cloud platform, as presented in Figure 10(a), and the terminal display system, as presented in Figure 10(b).

Among these parts, the central control system is installed on the management and control server, with data management, analysis management, terminal management, and user management along with other major functional modules, through which the monitoring data could be received, analyzed, published, and monitored, while all functional modules could be uniformly managed and controlled. The 


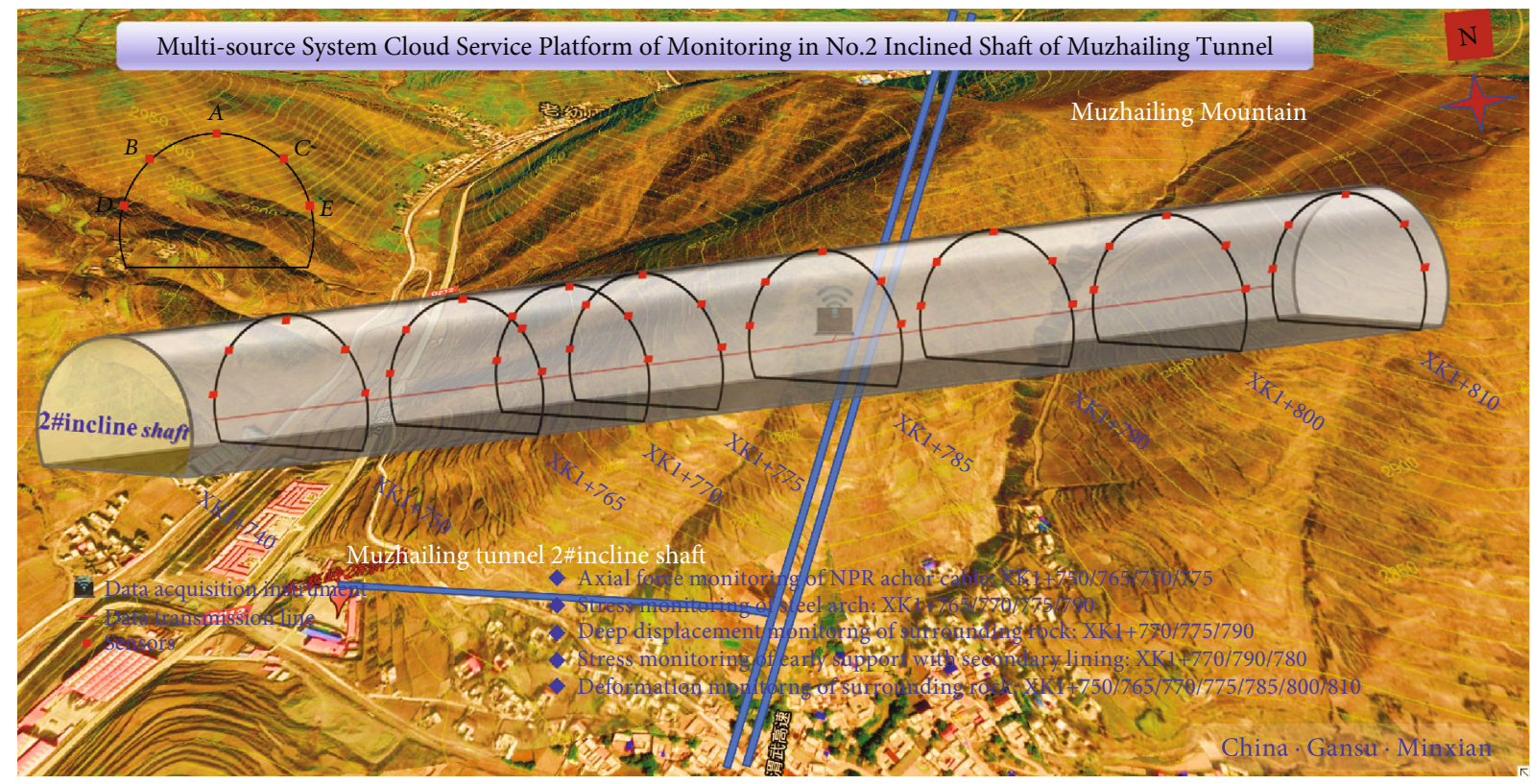

Figure 15: Monitoring section layout of the No. 2 inclined shaft in the Muzhailing tunnel.

network cloud platform is the information transmission bridge between the central control system and the terminal display system. The terminal display system includes terminal release, release of field data transmitted by the cloud server, automatic analysis, and generation of curves, along with real-time determination and monitoring of the safety and stability of the tunnel in the field, as presented in Figure 11.

The WEB platform has the following functions:

(1) With the background of the tunnel simulation map, the positions of the measuring points and each substation correspond to the graph, while the real-time information of each monitoring point is displayed intuitively. The graph could be scaled and moved, which is easy to be altered. The monitoring point status is refreshed in real-time

(2) Comprehensive data display, including curve display, bar chart display, and report display

(3) Data query function, including daily query and monthly query

(4) Overlimit alarm function

(5) Perform information editing and management functions for the monitoring system equipment

\section{Field Engineering Application}

5.1. Project Overview and Monitoring Design. The Muzhailing tunnel constituted a control project of the WeiYuan to $\mathrm{WuDu}$ section of the national highway from Lanzhou to Haikou (G75). The total length of the tunnel was $15.2 \mathrm{~km}$, the No. 2 inclined shaft was $1.813 \mathrm{~km}$ in length, and the maximum depth was 592 meters, having the entire level of class sur-

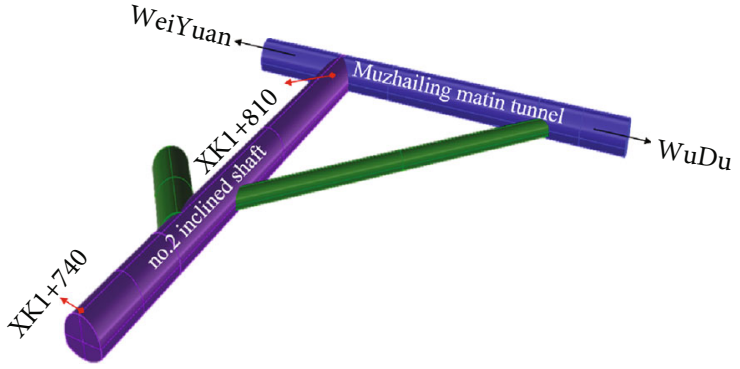

Figure 16: Position of the No. 2 inclined shaft in the Muzhailing tunnel.

rounding rock classification, with maximum horizontal principal stress of $24.95 \mathrm{MPa}$, while the $R_{c} / \sigma_{\max }$ was $<4$. It was a typical ultrahigh pressure soft rock tunnel. The surrounding rocks of the Muzhailing tunnel were relatively fractured and passed through the complicated geological structures, as presented in Figure 12. Since the construction of the No. 2 inclined shaft of the Muzhailing tunnel started in 2016, large deformation of the surrounding rock at multiple locations occurred, with a maximum deformation of $3145 \mathrm{~mm}$ and an arch replacement rate of up to $36 \%$, as presented in Figure 13.

On October 12, 2018, the soft rock large deformation control technology utilization of the NPR anchor cable tunnel was initially tested on-site. The support design of the NPR anchor cable included three-step construction processes, as presented in Figures 14(a) and 14(b), which constituted the first field test of a tunnel within the transportation industry. The tunnel support scheme was asymmetric long and with short NPR anchor cable combined support, as presented in Figure 14(a). As the surrounding rock of the left half of the tunnel was severely deformed and fractured, the left half of the tunnel was densely supported. The support density of the NPR long anchor cable in this area was higher than for the right half, while the other support parameters 


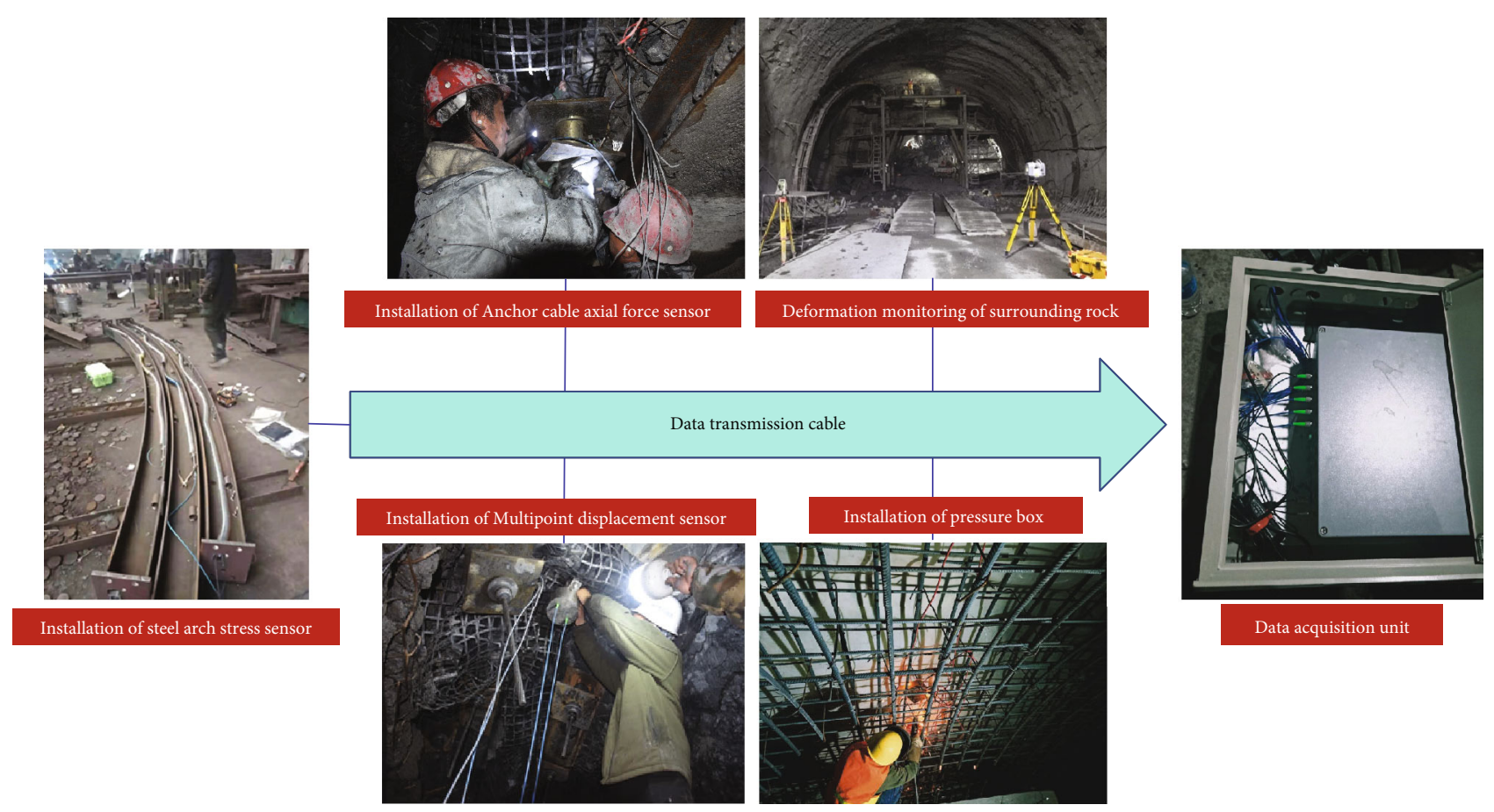

FIgURE 17: Installation of sensors unit of the No. 2 inclined shaft in the Muzhailing tunnel.

were the same. The specific performance was the longitudinal spacing of the NPR long anchor cable ring in the left half of the tunnel was $2000 \mathrm{~mm} \times 1200 \mathrm{~mm}$. The longitudinal spacing of NPR long anchor rings at the right half of the tunnel was $1000 \mathrm{~mm} \times 1200 \mathrm{~mm}$.

To effectively evaluate the NPR anchor cable soft rock large deformation control effect, while ensuring construction quality and safety, the multisource system cloud service platform of Monitoring in the No. 2 inclined shaft of the Muzhailing tunnel was established. The monitoring contents included axial force monitoring of the NPR anchor cable, stress monitoring of steel arch frame, deep displacement monitoring of surrounding rock, pressure monitoring of initial support with secondary lining, and deformation monitoring of the surrounding rock. The specific monitoring information is presented in Figure 15.

The position of the No. 2 inclined shaft of the Muzhailing tunnel is presented in Figure 16, while the monitoring section of the No. 2 inclined shaft is presented in Figure 15.

5.2. Sensor Installation and Monitoring Results. The sensor installation with multisource monitoring data information through the optical fiber transmission, as well as the demodulation with the data acquisition instrument is presented in Figure 17. The encrypted data was transmitted to the cloud server for calculation and storage through the wireless network, while the data were uploaded to the cloud platform for the terminal platform to call and analyze. The monitoring data were utilized for feedback design, to guide the NPR anchor cable construction.

5.2.1. Monitoring Results of NPR Anchor Cable Axial Force. After the construction completion of the NPR anchor cable,

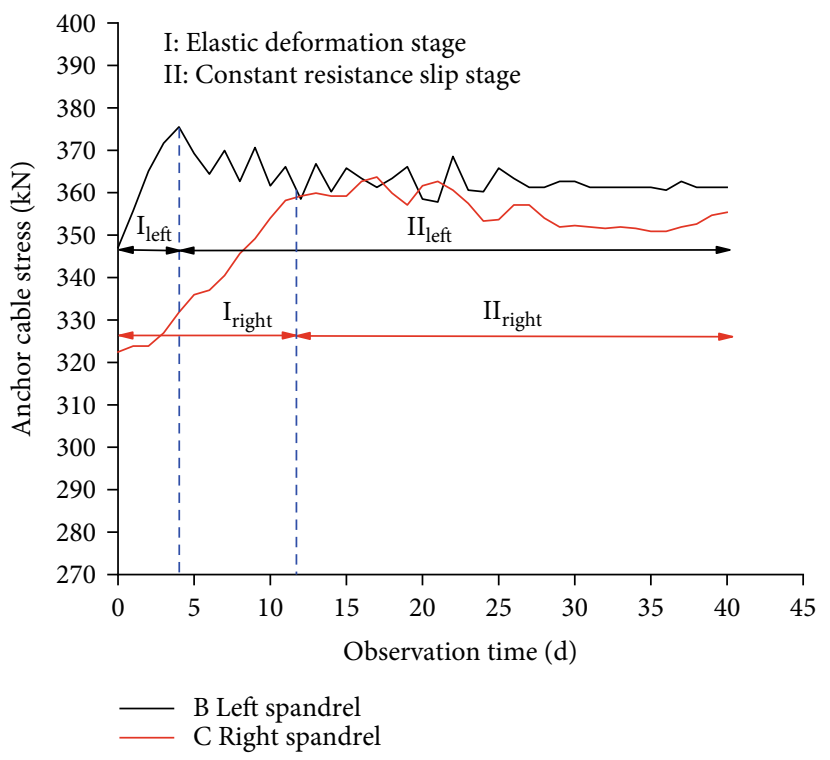

Figure 18: Axial force monitoring curve of the NPR anchor cable at section XK1+770.

the anchor cable dynamometer was installed at XK1 $+765 / 777 / 775 / 790$ sections. The control effect of the NPR anchor cable on the surrounding rock was evaluated through the axial force of NPR anchor cable monitoring. The characteristic section XK1+770 is presented in Figure 18. The axial force change of the anchor cable was executed in two stages: elastic deformation stage and constant resistance slip stage. In the elastic deformation stage, the elastic deformation of steel strand was mainly utilized to resist the cracking and expansion deformation of the surrounding rock. In the constant resistance sliding stage, the stress state of the 


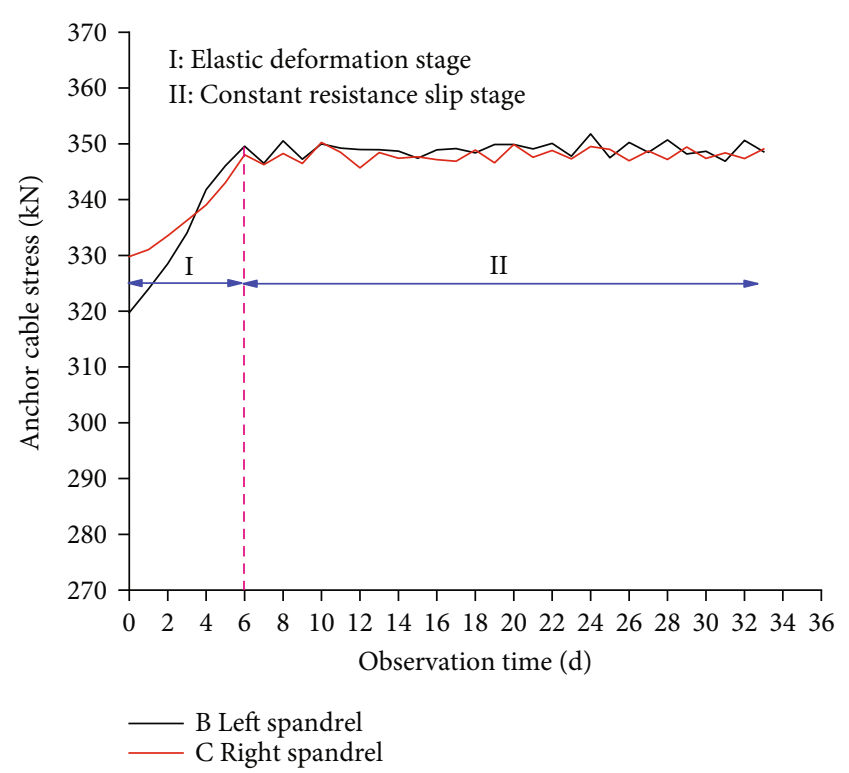

FIGURE 19: Axial force monitoring curve of the NPR anchor cable at section XK1+790.

surrounding rock was mainly adjusted by the NPR anchor cable constant resistance slip, to turn asymmetric stress characteristics into symmetric stress characteristics.

Due to the asymmetric stress characteristics of the left and right shoulders of the No. 2 inclined shaft of the Muzhailing tunnel, the NPR anchor cable of the left shoulder first entered the constant resistance slip stage after 4 days from installation, while the right shoulder entered the constant resistance slip stage after 12 days from installation. The force monitoring system truly reflected the adaptive adjustment of the NPR anchor cable support for the surrounding rock. The NPR anchor cable penetrated the constant resistance body slips, to uniformly release the deformation energy of the surrounding rock, turning the asymmetric stress state into a symmetrical uniform distribution load, which effectively controlled the large deformation of the soft rock inside the tunnel. In order to realize combined support, NPR anchor cable encryption asymmetric support was required on the tunnel left shoulder, to effectively uniformly deform the surrounding rock. The axial force curve of the XK1+790 anchor cable with characteristic cross-section is presented in Figure 19. Following monitoring and feedback design, the anchor cable was reinforced and supported at the left shoulder position. The asymmetric stress characteristics of the surrounding rock were significantly improved, fully demonstrating the adaptive adjustment of NPR anchor cables and surrounding rock. The large deformation of the jointed broken rock is caused by many factors $[35,36]$, but the NPR anchor cable with high preload is one of the effective ways to solve this problem [37].

5.2.2. Monitoring Results of Pressure on Steel Arch Frame. Subsequently, to the construction of the NPR anchor cable completion, the steel arch stress sensors were installed at the sections of XK1+765/770/775. The characteristic section $\mathrm{XK} 1+775$ is presented in Figure 20. The stress on the left and right shoulders of the steel arch exceeded the stress on the vault. The maximum pressure on the left shoulder was $150 \mathrm{MPa}$, which did not reach the yield strength value of the steel arch. The support system of the steel arch was in healthy operation. After the construction of the upper steps, the stress of the steel arch increased gradually. The excavation of the middle steps and the lower steps resulted in the arch temporary suspension, while the steel arch stress decreased. After the completion of the inverted arch, the pressure of the steel arch gradually tended to stabilize. In addition, 30 days after the completion of the steel arch, the entire support system force of the steel arch was basically stable, which further indicated that the surrounding rock deformation was effectively controlled, laying the foundation for the secondary lining trial.

5.2.3. Monitoring Results of the Deep Displacement of the Surrounding Rock. After the construction of the steel arch frame was completed, the multipoint displacement sensors were installed at the left shoulder positions of the XK1 $+770 / 775 / 790$ sections, for deep displacement real-time monitoring of the surrounding rock under the NPR anchor cable support system. The characteristic section XK1+790 is presented in Figure 21.

For the short anchor cable, the combined arch effect of the surrounding rock was utilized, to transform the surrounding rock into a uniform stress-bearing arch through multiple groups of anchor cables [38]. For the long anchor cable, the theory of suspension was utilized, to form a stress-strengthening arch through the stress-bearing arch through suspension, to resist the deformation of surrounding rock. It could be observed from Figure 21 that the deformation of surrounding rocks mainly occurred at the depths of $7 \mathrm{~m}$ and $10 \mathrm{~m}$, reaching $102 \mathrm{~mm}$. The displacement between the depths of $5 \mathrm{~m}$ and $7 \mathrm{~m}$ reached $58 \mathrm{~mm}$, indicating that the length of the long anchor cable must exceed 7 meters, to effectively control the deformation of surrounding rocks. After 30 days, the deep displacement of the surrounding rock was basically stable, while the deformation of the surrounding rock was effectively controlled.

5.2.4. Monitoring Results of Primary Support Structure Deformation. The deformation of the surrounding rock was measured with the total station. The arrangements of the monitoring sections were at XK1 + 750/765/770/775/785/ $795 / 800 / 810$. Five monitoring points were arranged for each monitoring section, while the monitoring results of XK1 + 795 are presented in Figure 22. It could be observed from the monitoring curve that the maximum deformation of the surrounding rock was located at the left arch spandrel of the tunnel, reaching $160 \mathrm{~mm}$, while the vault and right arch spandrel were approximately $90 \mathrm{~mm}$. After the excavation of the tunnel face, the subsidence rate of the left spandrel in the rapid deformation stage was $10 \mathrm{~mm} / \mathrm{d}$. After the completion of the middle step, the surrounding rock deformation entered the slow deformation stage, while the deformation rate dropped to $2 \mathrm{~mm} / \mathrm{d}$. The surrounding rock deformation was basically stable after 25 days. It could be observed from the monitoring curve that the application time of the second liner concrete should have been no less than 28 days after the tunnel face excavation completion. 


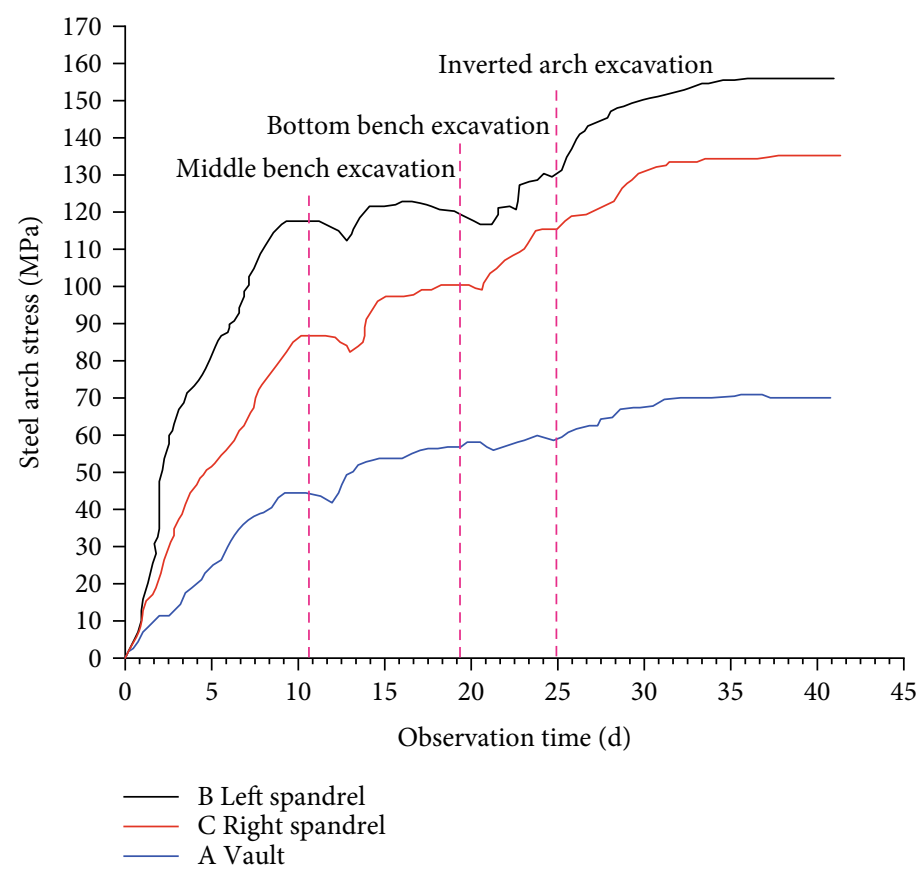

FIGURE 20: Stress monitoring curve of steel arch at section XK1+775.

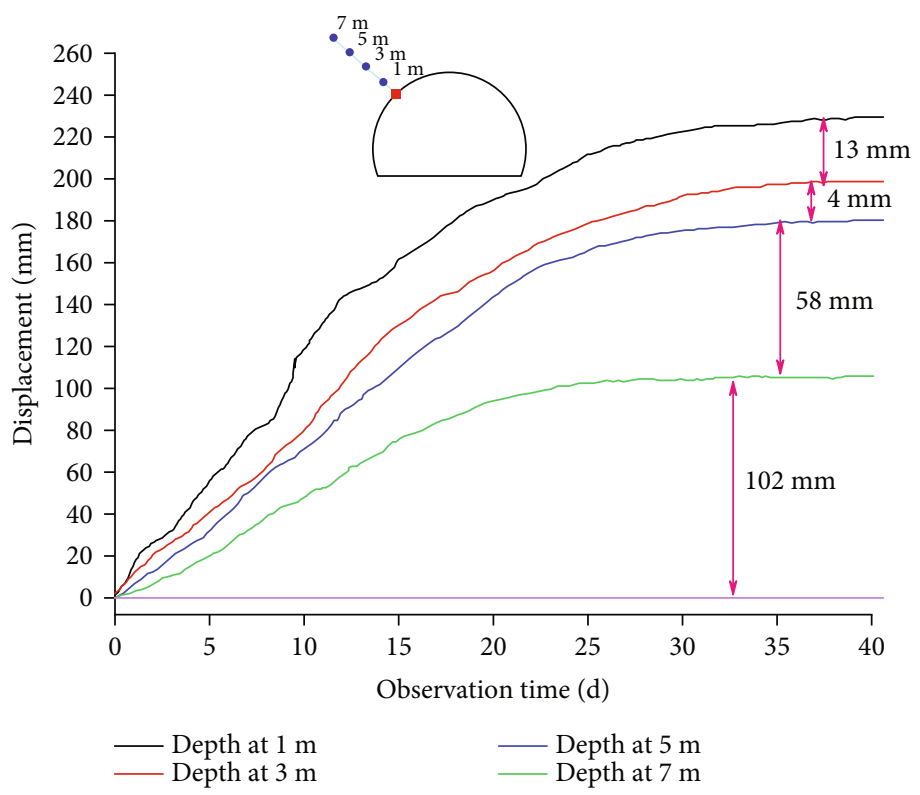

Figure 21: Monitoring curve of surrounding rock deep displacement at section XK1+ 775 .

5.2.5. Pressure Monitoring Results of Primary Support with Secondary Lining. The pressure monitoring between primary supports with secondary lining was of high significance to the evaluation of the primary support system and the healthy operation of the secondary lining. Fiber Bragg grating pressure sensors were installed at the sections of XK1 $+770 / 790 / 800$, respectively, while the characteristic section curve of XK1+800 is presented in Figure 23.

It could be observed that the maximum pressure between the primary supports with secondary lining was approximately $0.7 \mathrm{MPa}$, while the highest stress occurred at the vault and left shoulder, whereas the right shoulder pressure was approximately $0.6 \mathrm{MPa}$. The pressure of the left and right hances was approximately $0.3 \mathrm{MPa}$. The pressure value was quite lower than the yield strength of the secondary lining concrete. After the completion of the second liner for 30 days, the pressure of the primary support with the second liner remained stable, while the entire support system was in a healthy state of operation.

\section{Conclusions}

In this work, multisource information fusion technology was adopted to embed into the No. 2 inclined shaft of the 


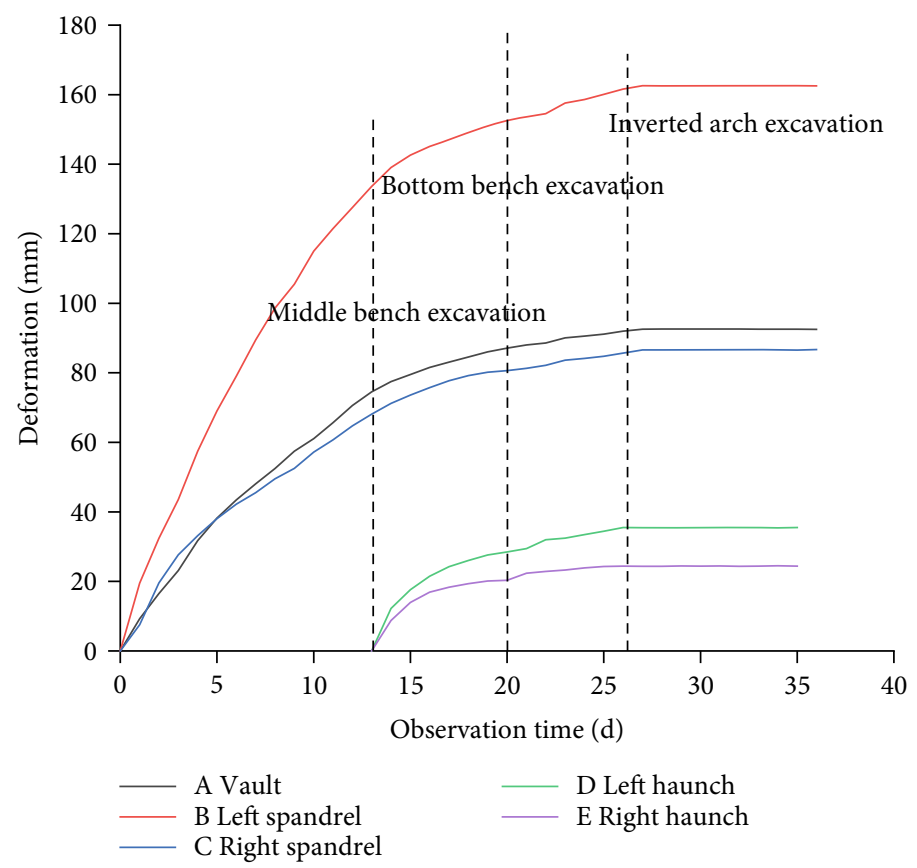

FIGURE 22: Deformation monitoring curve of the surrounding rock at section XK1+ 795.

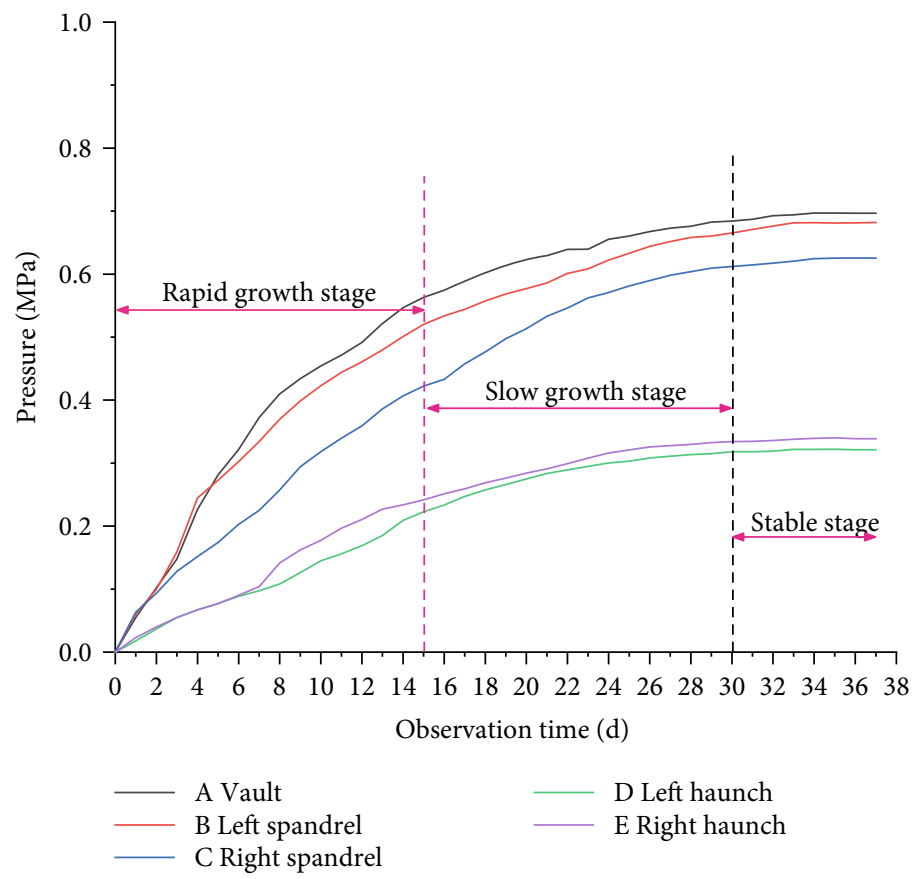

FIGURE 23: Stress monitoring curve of primary support and secondary lining at section XK1+800.

Muzhailing tunnel. The monitoring system provided the collection, transmission, storage, processing, and early warning information sending of data. The main conclusions are as follows:

(1) The cloud server was better than the traditional server in terms of elastic expansion, stability, and security. Based on the cloud platform server, a multisource information monitoring system was built for the No. 2 inclined shaft of the Muzhailing tunnel, through which the evaluation of the supporting effect of the new support technology of the NPR anchor cable on the tunnel with large deformation of the soft rock was solved

(2) Based on the FBG sensor with high accuracy and strong anti-interference ability, multisource monitoring information and publishing technology were integrated into one, and centralized monitoring of tunnel multiparameter information was successfully 
carried out. According to the feedback of the monitoring information, the reverse guidance of the NPR anchor cable support design played an important role in the large deformation control of the surrounding rock

(3) During multisource information monitoring, the axial force monitoring of the NPR anchor cable could effectively distinguish the asymmetric stress characteristics of the surrounding rock. Through asymmetric support of the NPR anchor cable, the load uniformity of the surrounding rock could be realized, effectively controlling the deformation of surrounding rock. The stress monitoring of steel arch was of high significance to the safety evaluation of the primary support structure. The monitoring of deep displacement could effectively verify the rationality of NPR anchor cable length. The monitoring of surrounding rock deformation could more directly reflect the control effect of the NPR anchor cable on the surrounding rock, also constituting the basis of reasonable time selection for secondary lining. The monitoring of contact pressure between the primary support structures with the second lining was of high significance to the uniform load evaluation on the second lining and to the structure safety

(4) The monitoring system had the characteristics of timely processing, intelligence, adaptability, and stability. Through prompt monitoring and dynamic design, the scientific nature of support design could be effectively guaranteed

\section{Data Availability}

The data are available and explained in this article; readers can access the data supporting the conclusions of this study.

\section{Conflicts of Interest}

The authors declare no conflict of interest.

\section{Authors' Contributions}

The manuscript was approved by all authors for publication.

\section{Acknowledgments}

The authors' are grateful for the contributions of Gansu Changda Highway Co., Ltd. and CCCC First Highway Fifth Engineering Co., Ltd. The authors gratefully acknowledge the financial support provided by the National Natural Science Foundation of China (Grant No. 41941018), Research and Development of Object-Oriented Photogrammetry by UAV (Unmanned Aerial Vehicle), and Rapid Deployment Monitoring and Early Warning Equipment on High-steep Slope (Grant No. 2019YFC1509604).

\section{References}

[1] Q. H. Qian and P. Lin, "Safety risk management of underground engineering in China: progress, challenges and strategies," Journal of Rock Mechanics and Geotechnical Engineering, vol. 8, no. 4, pp. 423-442, 2016.

[2] C. Zhu, X. Xu, W. Liu et al., "Softening damage analysis of gypsum rock with water immersion time based on laboratory experiment," IEEE Access, vol. 7, pp. 125575-125585, 2019.

[3] Y. Wang, B. Zhang, S. H. Gao, and C. H. Li, "Investigation on the effect of freeze-thaw on fracture mode classification in marble subjected to multi-level cyclic loads," Theoretical and Applied Fracture Mechanics, vol. 111, p. 102847, 2021.

[4] Z. G. Tao, C. Zhu, X. Zheng et al., "Failure mechanisms of soft rock roadways in steeply inclined layered rock formations," Geomatics, Natural Hazards and Risk, vol. 9, no. 1, pp. 11861206, 2018.

[5] Q. X. Meng, H. L. Wang, M. Cai, W. Xu, X. Zhuang, and T. Rabczuk, "Three-dimensional mesoscale computational modeling of soil-rock mixtures with concave particles," Engineering Geology, vol. 277, article 105802, 2020.

[6] P. Zhang, R. P. Chen, T. Dai, Z. T. Wang, and K. Wu, "An AIoT-based system for real-time monitoring of tunnel construction," Tunnelling and Underground Space Technology, vol. 109, p. 103766, 2021.

[7] W. Liu, J. Liu, and C. Zhu, "Multi-scale effect of acoustic emission characteristics of 3D rock damage," Arabian Journal of Geosciences, vol. 12, no. 22, 2019.

[8] Q. X. Meng, H. L. Wang, W. Y. Xu, M. Cai, J. Xu, and Q. Zhang, "Multiscale strength reduction method for heterogeneous slope using hierarchical FEM/DEM modeling," Computers and Geotechnics, vol. 115, p. 103164, 2019.

[9] C. Zhu, Z. Yan, Y. Lin, F. Xiong, and Z. Tao, "Design and application of a monitoring system for a deep railway foundation pit project," IEEE Access, vol. 7, pp. 107591-107601, 2019.

[10] W. Wang, L. Li, W. Xu, Q. X. Meng, and J. Lü, “Creep failure mode and criterion of Xiangjiaba sandstone," Journal of Central South University, vol. 19, no. 12, pp. 3572-3581, 2012.

[11] Q. X. Meng, L. Yan, Y. L. Chen, and Q. Zhang, "Generation of numerical models of anisotropic columnar jointed rock mass using modified centroidal voronoi diagrams," Symmetry, vol. 10, no. 11, p. 618, 2018.

[12] D. T. T. Chang, Y. S. Tsai, H. C. Lee, L. L. Guo, and K. C. Yang, "Wireless sensor network (WSN) using in tunnel environmental monitoring for disaster prevention," Advanced Materials Research, vol. 291-294, pp. 3401-3404, 2011.

[13] Z. Li, H. Liu, Z. Dun, L. Ren, and J. Fang, "Grouting effect on rock fracture using shear and seepage assessment," Construction and Building Materials, vol. 242, p. 118131, 2020.

[14] X. Yang, J. Wang, D. Hou, C. Zhu, and M. He, "Effect of drywet cycling on the mechanical properties of rocks: a laboratoryscale experimental study," PRO, vol. 6, no. 10, p. 199, 2018.

[15] L. Y. Ding, C. Zhou, Q. X. Deng et al., "Real-time safety early warning system for cross passage construction in Yangtze riverbed metro tunnel based on the internet of things," Automation in Construction, vol. 36, no. 12, pp. 25-37, 2013.

[16] Z. S. Pan, "Application of deformation monitoring technology in Wolong tunnel construction," Survey world, vol. 3, pp. 1720, 2018.

[17] Q. Jiang, S. Zhong, P.-Z. Pan, Y. Shi, H. Guo, and Y. Kou, "Observe the temporal evolution of deep tunnel's 3D 
deformation by 3D laser scanning in the Jinchuan No. 2 Mine," Tunnelling and Underground Space Technology, vol. 97, 2020.

[18] J. Cai, D. D. Zhang, and Y. Li, "Research progress of optical fiber sensing technology in geotechnical and geological engineering," Journal of architecture and civil engineering, vol. 32, no. 3, pp. 28-37, 2015.

[19] X. Zhao and H. Qiu, "Application of fiber Bragg grating sensing technology to tunnel monitoring," Yanshilixue Yu Gongcheng Xuebao/chinese Journal of Rock Mechanics \& Engineering, vol. 26, no. 3, pp. 587-593, 2008.

[20] Q. Liu, J. Chai, S. Chen, D. Zhang, Q. Yuan, and S. Wang, "Monitoring and correction of the stress in an anchor bolt based on pulse pre-pumped brillouin optical time domain analysis," Energy Science \& Engineering, vol. 8, no. 6, pp. 2011-2023, 2020.

[21] Y. Ding, P. Wang, N. He, C. Liang, and B. B. Ma, "A new method to measure the deformation of shield tunnel based on FBG," Chinese Journal of Underground Space and Engineering, vol. 12, no. 5, pp. 1320-1325, 2016.

[22] W. A. Jing, L. Shucai, S. H. Bin et al., "Trifarious FBG sensor strain transfer characteristics and its application to tunnel excavation model test," Journal of Engineering Geology, vol. 21, 2013.

[23] Z. H. Zhu, D. C. Ren, X. W. Li, J. H. Sun, and W. S. Wang, "Application of fiber Bragg grating displacement meter groups in continuous monitoring of deformation of surrounding rock," Chinese Journal of Geotechnical Engineering, vol. 38, no. 11, 2016.

[24] H. F. Pan, Q. Yang, K. M. Zhou, Y. Ding, Y. J. Qian, and M. D. Zhang, "Application of FBG strain sensor in safety monitoring of the secondary lining of diversion tunnel," Dam \& Safety, vol. 2, pp. 11-13, 2016.

[25] Z. C. Cai, The Study of FBG Sensor in Monitoring Secondary Lining and Surrounding Rock Pressure in Highway Tunnel, [M. S. Thesis], Kunming University of Science and Technology, 2013.

[26] Z. Tao, H. Zhang, Y. Peng, Y. Yu, and G. Xuebao, "Frame structure and engineering applications of multi-source system cloud service platform for landslide monitoring," Chinese Journal of Rock Mechanics \& Engineering, vol. 36, no. 7, pp. 1649-1658, 2017.

[27] Z. H. Honghu, W. A. Deyang, W. A. Baojun, Z. H. Bao, and S. H. Bin, "Experimental study on pipe-soil interaction using fiber optic sensing and digital imageanalysis," Journal of Engineering Geology, vol. 28, no. 2, pp. 317-326, 2020.

[28] M. C. He, W. L. Gong, J. Wang et al., "Development of a novel energy-absorbing bolt with extraordinarily large elongation and constant resistance," International Journal of Rock Mechanics \& Mining Sciences, vol. 67, no. 4, pp. 29-42, 2014.

[29] Z. Tao, C. Zhu, X. Zheng, and M. He, "Slope stability evaluation and monitoring of Tonglushan ancient copper mine relics," Advances in Mechanical Engineering, vol. 10, no. 8, 2018.

[30] Z. G. Tao, Z. Zhu, W. S. Han et al., "Static tension test and the finite element analysis of constant resistance and large deformation anchor cable," Advances in Mechanical Engineering, vol. 10, no. 12, 2018.

[31] Y. J. Wang, M. C. He, K. X. Zhang et al., "Strata behavior characteristics and control countermeasures for the gateroad surroundings in innovative non-pillar mining method with gateroad formed automatically," Journal of Mining and Safety Engineering, vol. 35, no. 4, pp. 677-685, 2018.

[32] T. A. O. Zhi-gang, L. I. Hai-peng, S. U. N. Guang-lin, Y. Li-jie, and Z. Xiu-lian, "Development of monitoring and early warning system for landslides based on constant resistance and large deformation anchor cable and its application," Rock and Soil Mechanics, vol. 36, no. 10, 2015.

[33] X. Qi, B. W. Geng, and Y. C. Chen, "Urban road waterlogging monitoring system based on cloud server," Microcontrollers and Embedded Systems, vol. 15, no. 11, pp. 37-39, 2015.

[34] J. J. Wang, Z. H. Lu, J. Wu, and Y. P. Zhong, "Cloud computing technology development analysis and applications discussion," Computer Engineering and Design, vol. 31, no. 20, pp. 4-9, 2010.

[35] L. L. Yang, W. Y. Xu, Q. X. Meng, and R. B. Wang, "Investigation on jointed rock strength based on fractal theory," Journal of Central South University, vol. 24, no. 7, pp. 1619-1626, 2017.

[36] Z. Li, S. Liu, W. Ren, J. Fang, Q. Zhu, and Z. Dun, "Multiscale laboratory study and numerical analysis of water-weakening effect on shale," Advances in Materials Science and Engineering, vol. 2020, Article ID 5263431, 14 pages, 2020.

[37] C. Zhu, M. C. He, M. Karakus, X. Cui, and Z. Tao, "Investigating toppling failure mechanism of anti-dip layered slope due to excavation by physical modelling," Rock Mechanics and Rock Engineering, vol. 53, no. 11, pp. 5029-5050, 2020.

[38] Q. X. Meng and W. Wang, "A novel closed-form solution for circular openings in generalized Hoek-Brown media," Mathematical Problems in Engineering, vol. 2014, 7 pages, 2014. 